\title{
Economic and Easy Manufacturing Method to Obtaining Dental Pieces
}

\author{
M.C. Aragón-Duarte ${ }^{1}$, M.H. Bocanegra B., A. Reyes-Rojas ${ }^{1}$, J.A. Duarte Moller, H.E. Esparza-Ponce ${ }^{1}$ \\ 1. Departamento de Física, Centro de Investigación en Materiales Avanzados S.C. (CIMAV), Chihuahua, \\ México.
}

Natural wear of the teeth, dental cavities, accidents and other dental diseases are some of the reasons by which a people lose their teeth and need a dental replacement. Yttria-stabilized tetragonal zirconia polycrystals (3Y-TZP) is being widely used in dental restorations [1-4], due to this material has biocompatibility and excellent mechanical strength; color as similar to natural teeth [5-6]. CAD/CAM system is currently being used, it famous method that consists to machining a presintered piece; which previously through a process of grinding, pressing and pre-sintering, and later machined by CAD/CAM, where the loss of material is around $60 \%$. Finally, the piece is sintering.

Other method that can be used is slip casting that consists in the preparation of a suspension with a specific percentage of solids and rheological properties, emptying the suspension on a plaster mold [7]. Aluminum patterns of the molars are formed with $20 \%$ larger than its original size, the process continues with a drying step and elimination of organic components with a subsequent sintering. Slip casting can be the possible solution to replace $\mathrm{CAD} / \mathrm{CAM}$ and use only the powders necessary to molars approximately 1.6 to $2 \mathrm{~g}$; this will depend on the size of the piece.

The present work were prepared suspension to slip casting with 70\% solids, water and gum Arabic solution $(10 \% \mathrm{Wt})$, evaluated the time to remove the solution and shape the wall of the tooth deposited on the plaster mold. Microstructural analyze of the samples were carried out by Scanning Electron Microscopy, crystallinity and identification of phases were verified by X-ray diffraction (XRD) analysis using a diffractometer PAnalytical. Diffraction patterns were acquired from 20 to $100^{\circ} 2 \theta$ using a Scanning speed of $0.2 \% \mathrm{~min} \mathrm{~K} \alpha \mathrm{Cu}$ radiation.

The results are shown in the Figure 1a) aluminum patron $20 \%$ larger than its original size and typical structures of dental piece obtained by b) CAD CAM and c) Slip casting, they are very similar. In the Figure 2a) are shown the diffractograms of two pieces in green and their difractograms after sintering. It observed that during the preparation of the slip and formed in green of the pieces, there is the presence of a monoclinic phase, which when subjected to sintering changes totally to a tetragonal phase, and they were identified by the ICDD card 00-083-0113 tetragonal and 00-80-0966 monoclinic phase. Besides the figure, No.2 shows morphology by SEM general aspect CAD CAM b) green, c) sintered and Slip casting d) green and e) sintered.

Six important things for dental applications should be considered: esthetic, marginal adaptation, biocompatible, mechanical strength, cost and easy manufacturing. the zirconia has the first 4 and with slip casting is possible reduce the time and cost, it means with this process only 1.6 to 2 grams of powder is used compared to the double that is required to form a piece by CAD CAM and avoid the steps previous (grinding, pressing and pre-sintering). Slip casting is a conventional method but using the modern techniques of scanning will allow us to avoid long processes and costs for the elaboration of dental pieces. Elaborating a metallic mold to form the plaster mold that can be recycled and reproducing the exact shape of the tooth before removing cavities [8]. 


\section{References:}

[1] Chevalier, J. et al, Journal of the American Ceramic Society, 82 (1999), p. 2150.

[2] Chevalier, J. et al, Annual Review of Materials Research 37 (2007), p. 1.

[3] K.Nakamu raa et al, Journal of the Mechanical Behavior of Biomedical Materials, 53 (2016), p. 301.

[4] M.C. Aragón-Duarte, et al, Ceramics International 43 (2017), p. 3931.

[5] Piconi, C. and Maccauro, G. Biomaterials 20 (1999), p. 1.

[6] Manicone, et al, Journal of Dentistry, 35 (2007), p. 819-826.

[7] H.E. Esparza-Ponce, Optimización de las propiedades reológicas del Sistema ZrO2-CaO, master degree 1996.

[8] Authors wish to express their appreciation to E. Guerrero for his technical work and assistance. M.C. Aragon wants to thank CONACYT Mexico for scholarship.

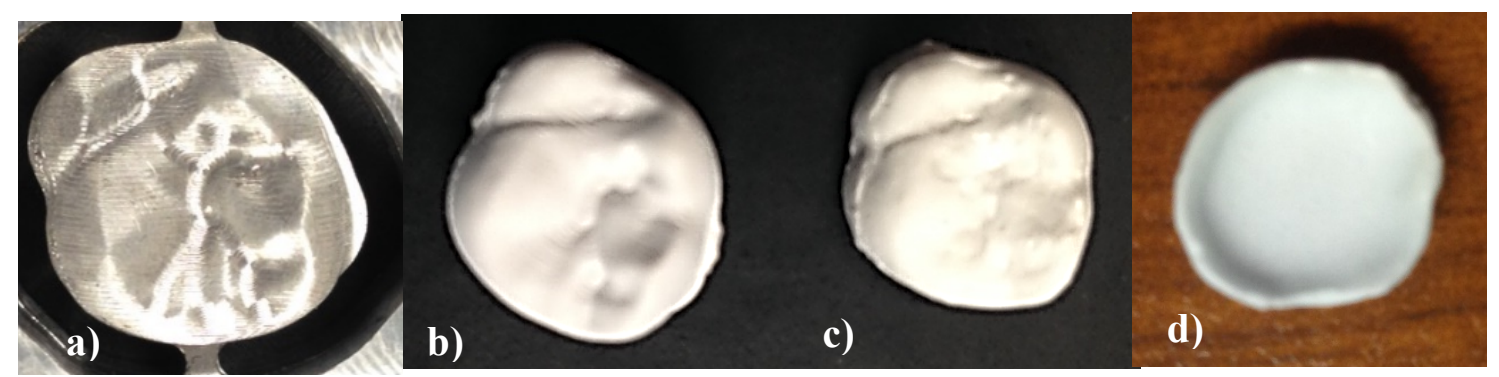

Figure 1. Pictures of a) aluminum patter, tooth by b) CAD CAM, c) frontal and d) rear Slip casting.
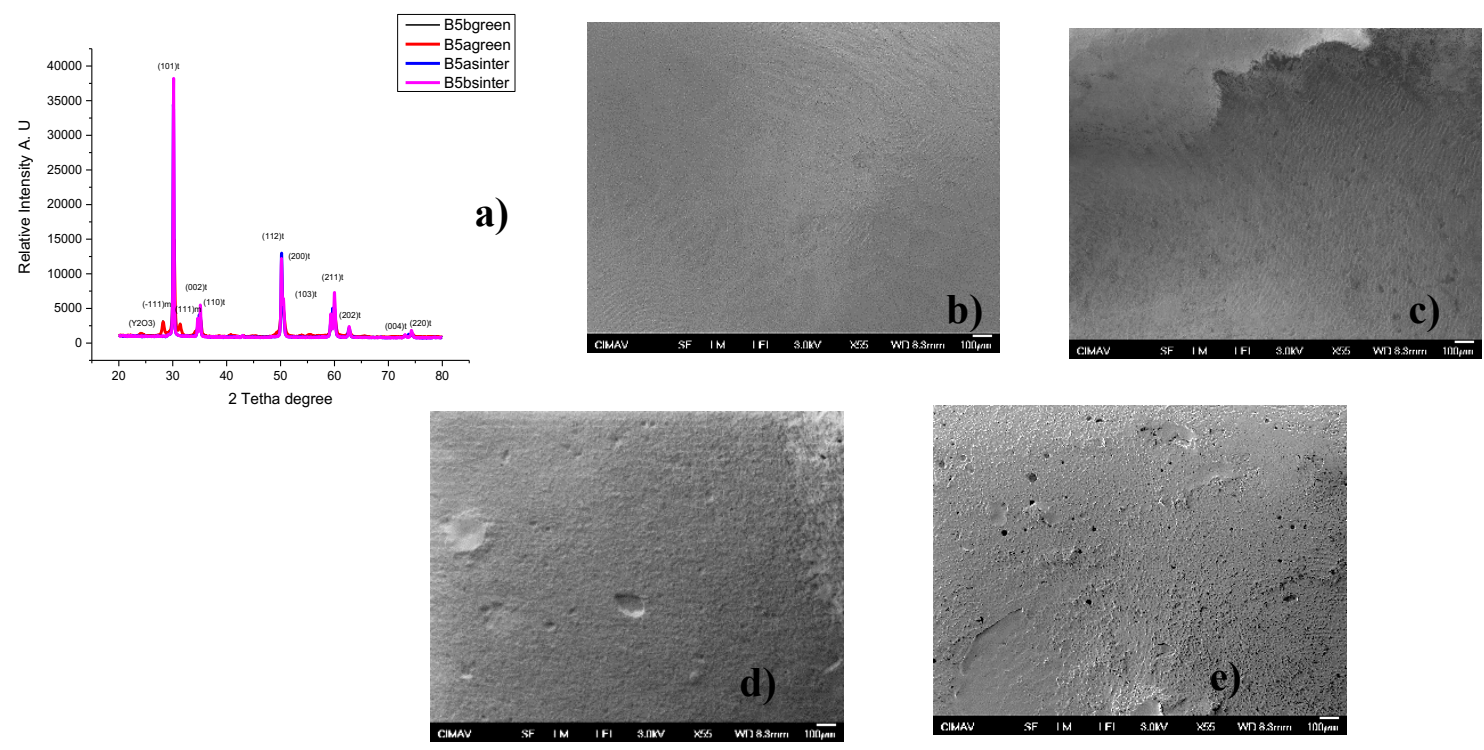

Figure 2. a) XRD diffractometers for two samples green and sintering, b-f) Morphology by SEM of grinder`s surface processed by CAD CAM b) green, c) sintering, slip casting d) green and e) sintering. 